\title{
Effect of Injection of Hatching Eggs in Different Concentrations of Nano Silver at Age 17.5 Days of Embryonic Age in Some Histological Traits of Broiler Ross 308
}

\author{
Nashwan Majeed Ali Al-Gburi' ${ }^{1}$, Fadhel Rasoul Abbas Al-Khafaji ${ }^{2}$, Hashem Hadi Dekhil Al-Gburi ${ }^{3}$ \\ ${ }^{1}$ Lecturer, University of Babylon/DNA Research Center, ${ }^{2}$ Prof., Lecturer, University of Al-Qasim Green-College of \\ Agriculture/Animal Production Department
}

\begin{abstract}
This study was conducted in the hatchery belonging to Al-Anwar Poultry Company,by injecting the hatching eggs at the age of 17.5 days from the age of the embryos with nano Silver, after that, and raised hatching chicks from the injected eggs in the field of poultry belonging to the Department of Animal Production, College of Agriculture, University of Al-Qasim Green for the period from 6/8/2017 until 9/9/2017, and after that the laboratory work was done, as it used 168 broiler chickens and was reared in cages $1 \mathrm{x} 1.5 \mathrm{~m}$, the chicks were randomly divided into seven treatments, and each treatment had three replicates, including each replicate of 8 chicks. Nano-silver was used by injecting it into the eggs in concentrations $(0,4,6,8,10,12,14$ $\mathrm{ppm})$ for treatments $(\mathrm{T} 1, \mathrm{~T} 2, \mathrm{~T} 3, \mathrm{~T} 4, \mathrm{~T} 5, \mathrm{~T} 6, \mathrm{~T} 7)$ respectively, The chicks were raised in the field for a period of 35 days, and in this study we reached the following results, a significant excelled $(\mathrm{P}<0.01)$ of the T3 treatment in the length and width of the villi in the Jejunum and the excelled of the two treatments T3,T7 in the depth of crypts of Lieberkuhn, and in the ileum there was a significant excelled $(\mathrm{P}<0.01)$ for the treatment $\mathrm{T} 2$ in the villi length, while the treatment $\mathrm{T} 7$ excelled in the villi width and the treatment $\mathrm{T} 5$ and T6 treatment was excelled in the crypts depth
\end{abstract}

Keywords: Broiler Ross 308, Nano silver, Histological traits.

\section{Introduction}

The poultry industry has recently witnessed multiple technologies, including nanotechnology, which is the study of materials on the Nano scale, where the size of the particles ranges between $(1-100)$ nanometers ${ }^{(4,11)}$, where nanomaterial's are distinguished in that they take up a very small area but it has relatively large surface areas, and as a result, when massive materials are reduced to Nano, their surface becomes chemically more effect and the physical properties of the material change without changing their chemical properties ${ }^{(4)}$. The expansion of the ratio of the surface area to the volume allows the nanoparticles to be more diversified and hence more frequent, as nanomaterial's can be used alone or carrying other materials for the purpose of connecting them inside the body or coated with other materials ${ }^{(21)}$, and the nanoparticles have been used as diagnostic and therapeutic agents in the medical field Human for some time, although its application in veterinary medicine and animal production is still relatively new. In recent times, the demands for the production of nanomaterial's and their uses in the poultry industry have increased due to the fact that the use of antibiotics as a treatment for disease infections of birds has become ineffective due to the increase in cases of bacteria resistant to antibiotics ${ }^{(16)}$ and this determines the need to find suitable alternatives, as the nanoparticles As a good antimicrobial to improve the growth of birds ${ }^{(9)}$. The sources showed that the injection of Nano-silver increased the immunity of the incubated chicks ${ }^{(17),(10,13,14)}$ indicated that the injection of hatching eggs with Nano-silver promoted the absorption of yolk fat in embryos and stimulated growth and embryonic development where the Nano-silver is silver Nano is an anti against a large number of germs. ${ }^{(2)}$ also indicated that the injection of hatching eggs with silver nanoparticles at concentrations $(12,14,16,18$ $\mathrm{ppm}$ ) increased the length and width of villi, therefore the present study aims to know the effect of injecting hatching eggs at the age of 17.5 days from the age of embryos at different levels of Nano-silver in some 
hatching traits and in the histological traits of the chicks hatched and determining the best level of injection.

\section{Materials and Method}

Salt solution $(\mathrm{NaCl})$ was used in the preparation of egg injection solutions. A Nano-silver material was obtained from the Nanosany Corporation company (20nm) and morphological (spherical).Use 168 broiler chickens and raised in cages $1 \times 1.5 \mathrm{~m}$. The chicks were randomly divided into four treatments. Each treatment included three replicates, each replicate included 8 chicks. Nano-silver was used by injection into eggs at concentrations $(0,4,6,8,10,12,14 \mathrm{ppm})$ for treatments (T1,T2,T3,T4,T5,T6,T7) respectively, where hatching eggs were injected at the age of 17.5 days From the age of the embryos and injected $(0.25 \mathrm{ml} / \mathrm{egg})$.

Feed Treatment: The chicks were fed on the starter diet from the age of one day until the third week of the bird's life, after that they were replaced by the final diet (finisher) until the end of the fifth week. Feed and water were provided in a free manner (ad libitum) and the diet used is as shown in the table below.

Table 1: Shows the percentages of diet components in the study and their chemical composition

\begin{tabular}{|l|c|c|}
\hline Feeding Materials & $\begin{array}{c}\text { \% Starter } \\
\text { Diet }\end{array}$ & $\begin{array}{c}\text { \% Final } \\
\text { Diet }\end{array}$ \\
\hline Yellow corn & 30 & 40 \\
\hline Wheat & 28.25 & 24 \\
\hline Soybean meal (48\%protein) & 31.75 & 24.8 \\
\hline Protein concentrate * & 5 & 5 \\
\hline Sunflower oil & 2.9 & 4.4 \\
\hline Limestone & 0.9 & 0.6 \\
\hline DCP Calcium Diphosphate & 0.7 & 0.9 \\
\hline Salt & 0.3 & 0.1 \\
\hline Mix vitamins and minerals & 0.2 & 0.2 \\
\hline Total & $\mathbf{1 0 0}$ & $\mathbf{1 0 0}$ \\
\hline General protein (\%) & 23 & 20 \\
\hline $\begin{array}{l}\text { Calculated energy represented (kilo } \\
\text { calories/kg feed) }\end{array}$ & 3027 & 3195.3 \\
\hline Lysine (\%) & 1.2 & 1.1 \\
\hline Methaionine (\%) & 0.49 & 0.46 \\
\hline Cystine (\%) & 0.36 & 0.32 \\
\hline Methaionine+cysteine (\%) & 0.85 & 0.76 \\
\hline Available phosphorus (\%) & 0.45 & 0.49 \\
\hline C/P\% & 131.61 & 159.77 \\
\hline
\end{tabular}

*BROCON-5 SPECIAL W protein concentrate: Chinese origin, each $\mathrm{kg}$ contains: $40 \%$ crude protein, $3.5 \%$ fat, $1 \%$ fiber, $6 \%$ calcium, $3 \%$ phosphorous available, $3.25 \%$ lysine, $3.90 \%$ methionine + cysteine $2.2 \%$ sodium, $2100 \mathrm{kcal} / \mathrm{kg}$ energy represented,20,000 IU vitamin A, 40000 IU vitamin D3, $500 \mathrm{mg}$ vitamin E,30 mg vitamin $\mathrm{K} 3,15 \mathrm{mg}$ vitamin $\mathrm{B} 1+\mathrm{B} 2,150 \mathrm{mg}$ B3,20 mg B6,300 B12 mg, $10 \mathrm{mg}$ folic acid, $100 \mathrm{mcg}$ biotin,1 mg iron,100 mg copper, $1.2 \mathrm{mg}$ manganese, 800 $\mathrm{mg}$ zinc, $15 \mathrm{mg}$ iodine, $2 \mathrm{mg}$ selenium, $6 \mathrm{mg}$ cobalt, 900 $\mathrm{mg}$ antioxidant (BHT).** According to the chemical analysis of the diet according to NRC ${ }^{(15)}$.

Preparing the histological sections: The two birds were slaughtered from each replicate. The tissue samples were taken for the shortest possible time period to ensure that the bird's body tissue is not damaged. A section (2 $\mathrm{cm}$ ) in length was taken from the second part of the small intestine (jejunum). The contents of the intestine were removed, all the sections taken with tap water were washed and the processes of preparing the histological sections were performed, according to him $^{(16)}$.

Examination of histological sections: The histological sections were examined using a compoundtype Olympus $\mathrm{BH} 2$ of Japanese origin. The histological sections were imaged by a digital camera attached to a Lenovo computer. The small intestine(jejunum) were examined using an accurate ocular micrometer of 100x magnification for the purpose of recording measurements of the small intestine (villi length, villi width and crypts depth) in microns $10-3 \mathrm{~mm}$, and used the stage micrometer for the purpose of Calibration of the Eyepiece according to what he mentioned ${ }^{(6)}$. The villi length was measured from the top of the villi until its association with the villi mysteries, while the crypt depth was defined as the depth or distance of immersion between adjacent villi ${ }^{(3,8)}$. As for the villi width, it was measured according to what he mentioned ${ }^{(3)}$. It was measured from the middle of the villi height or from the curvature of the villi that divides the villi while ${ }^{(5)}$ the villi width was estimated from the base of the villi, so the villi width was measured ${ }^{(3)}$ by taking the average for the two readings, knowing that all measurements were made for ${ }^{(10)}$ readings for each measurement and taking average.

Statistical Analysis: The statistical program ${ }^{(18)}$ was used in data analysis to study the effect of different factors on the studied traits according to a completely randomized design (CRD), and The significant 
differences between the averages were compared to the Duncan $^{(7)}$ polynomial test

\section{Mathematical Model:}

$$
\mathrm{Yij}=\mu+\mathrm{Ti}+\mathrm{eij}
$$

\section{Results and Discussion}

The length and width of the villi and crypts depth in the Jejunum and Ileum: Table (3) shows the effect of injecting hatching eggs with Nano silver on the length and width of the villi and the crypts depth in the Jejunum at the age of 35 days from the age of birds. While T3 treatment was significantly excelled $(\mathrm{P}<0.01)$ on villi length traits on the rest of the treatments followed by treatments $\mathrm{T} 7$ and $\mathrm{T} 4$, respectively. While treatment $\mathrm{T} 2$ excelled on the treatments $\mathrm{T} 1, \mathrm{~T} 5$, and $\mathrm{T} 6$, while treatment $\mathrm{T} 6$ excelled on treatments $\mathrm{T} 1, \mathrm{~T} 5$, while the T5 excelled on control treatment T1.As for the villi width, the $\mathrm{T} 3$ treatment continued to excel, as $\mathrm{P}<0.01$ ) significantly excelled on the rest of the treatments, while the $\mathrm{T} 2$ treatment was excelled on the T1,T4,T5,T6,T7 treatments, while the $\mathrm{T} 4, \mathrm{~T} 5$ treatments were excelled on the $\mathrm{T} 1, \mathrm{~T} 6, \mathrm{~T} 7$ treatments. The $\mathrm{T} 7$ and $\mathrm{T} 6$ treatments were excelled on the control treatment $\mathrm{T} 1$ and there was no significant difference between the treatments $\mathrm{T} 4, \mathrm{~T} 5$ and T6, T7 treatments. At the Lieberkuhn crypts depth, the $\mathrm{T} 3, \mathrm{~T} 7$ treatments were significantly excelled on the rest of the treatments while the T5, T4, T2 treatments were excelled to the $\mathrm{T} 1$ and $\mathrm{T} 6$ treatments, and no significant difference occurred between $\mathrm{T} 2, \mathrm{~T} 4, \mathrm{~T} 5$ treatments, while the T6 treatments was excelled on treatments T1. In the Ileum, Table (4) showed a significantly excelled $(\mathrm{P}<0.01)$ in the villi length traits for the $\mathrm{T} 2$ treatment on the rest of the treatments and the T6, T7 treatments were excelled on the T1, T3, T4, T5 treatments and the $\mathrm{T} 3$ treatment was excelled on the T1, T4, T5 treatments, While treatments $\mathrm{T} 5$ was excelled on treatments $\mathrm{T} 1$ and T4,The T4 treatment was excelled on the T1 treatment. In the villi width,P7 treatment was significantly excelled on the $\mathrm{T} 7$ treatment, and the $\mathrm{T} 2, \mathrm{~T} 3$ treatments were excelled on the $\mathrm{T} 1, \mathrm{~T} 4, \mathrm{~T} 5$ and $\mathrm{T} 6$ treatments, and the T4 and T6 treatment excelled on the T1 and T5 treatments. While the T5 treatment was excelled on the T1 treatment and in the crypts depth,the T5,T6 treatments were significantly excelled on the rest of the treatments, and the T3,T7 treatments were excelled on the $\mathrm{T} 1, \mathrm{~T} 2, \mathrm{~T} 4$ treatments, and the $\mathrm{T} 2, \mathrm{~T} 4$ treatments on the T1 treatment. ${ }^{(18)}$ mentioned that nano-silver could affect the outer layer of the intestinal wall and consequently a change in the length and width of villi and depth of crypts also found ${ }^{(12)}$ that feeding on nanosilver at a concentration of $5 \mathrm{mg} / \mathrm{kg}$ feed resulted in an increase of $11 \%$ in the average length And the width of villi and $7 \%$ in the depth of crypts and the reason may be due to the fact that nano-silver improved the intestinal environment and thus led to an increase in the length and width of villi and depth of crypts, This study agrees with $^{(2)}$, which found that the injection of hatching eggs with nanosilver at concentrations $(12,14,16,18 \mathrm{ppm})$ improved the intestinal environment because it is a bacterial antagonist, it increases the length and width of villi and depth of crypts. The histological sections of the Jejunum region of the small intestine of different nanosilver injection treatments were studies, The results showed a significant increase in the length and width of villi and regularity of their forms, as well as an increase in crypts depth for injection treatments at the age of 35 days compared to the positive and negative control treatments (images 1-7), Also, the cellular activity in the intestine sections showed an increase through the multiplication of intestinal cells in the crypts region, as well as in the surface of villi, especially in injections with nano-silver at a concentration of (4 ppm), as another section appears in the Jejunum region to treat the injection with a concentration (6 ppm), which shows an increase in the width and regularity of villi, In the Ileum, we note the treatment of injections with a concentration of (8 ppm). The regularity of the villi forms appeared with the increase of their lengths and the appearance of cell propagation in the crypts of Lieberkuhn. As for the injections with a concentration of $(10,12,14 \mathrm{ppm})$. The prolongation of the villi appears with its regularity and an increase in cellular activity in the crypts region. As for the control treatment, it is found that the length and width of the villi are varied and their forms are irregular. And the reason for the excelled of the nano-silver injection treatments to the control treatment may be that the nano-silver injection into the Amniotic fluid of the embryo is swallowed orally by the fetus in the last third of the incubation (19 days), which causes the activity of the gastrointestinal tract in general and the gut region and in the Jejunum, in particular,This led to an increase in the length and width of villi and an increase in crypts $\operatorname{depth}(1)$. 
Table 2: The effect of injecting hatching eggs with nanosilver on the length and width of villi and crypts depth in the Jejunum for broilers.

\begin{tabular}{|l|c|c|c|}
\hline \multirow{2}{*}{ Treatments } & \multicolumn{3}{|c|}{ Average \pm standard error (mm) } \\
\cline { 2 - 4 } & Length of villi & width of villi & Depth of crypts \\
\hline T1 & $8.07 \pm 0.12 \mathrm{f}$ & $1.59 \pm 0.05 \mathrm{e}$ & $2.27 \pm 0.02 \mathrm{~d}$ \\
\hline T2 & $9.87 \pm 0.07 \mathrm{~d}$ & $2.80 \pm 0.05 \mathrm{~b}$ & $3.09 \pm 0.01 \mathrm{~b}$ \\
\hline T3 & $11.45 \pm 0.05 \mathrm{a}$ & $3.15 \pm 0.03 \mathrm{a}$ & $3.37 \pm 0.05 \mathrm{a}$ \\
\hline T4 & $11.09 \pm 0.03 \mathrm{~b}$ & $2.36 \pm 0.02 \mathrm{c}$ & $2.98 \pm 0.06 \mathrm{~b}$ \\
\hline T5 & $6.53 \pm 0.03 \mathrm{~g}$ & $2.27 \pm 0.05 \mathrm{c}$ & $3.00 \pm 0.05 \mathrm{~b}$ \\
\hline T6 & $9.17 \pm 0.01 \mathrm{e}$ & $1.84 \pm 0.01 \mathrm{~d}$ & $2.47 \pm 0.03 \mathrm{c}$ \\
\hline T7 & $10.56 \pm 0.04 \mathrm{c}$ & $1.87 \pm 0.01 \mathrm{~d}$ & $3.43 \pm 0.01 \mathrm{a}$ \\
\hline Level of significance & $* *$ & $* *$ & $* *$ \\
\hline
\end{tabular}

The averages that have different letters within one column differ significantly among themselves at the level of $* *(\mathrm{P}<0.01)$. The $\mathrm{T} 7, \mathrm{~T} 6, \mathrm{~T} 5, \mathrm{~T} 4, \mathrm{~T} 3, \mathrm{~T} 2, \mathrm{~T} 1$ treatments are a control treatment without injection and injection, at concentrations of $14,12,10,8,6,4$ of the silver nano solution, respectively
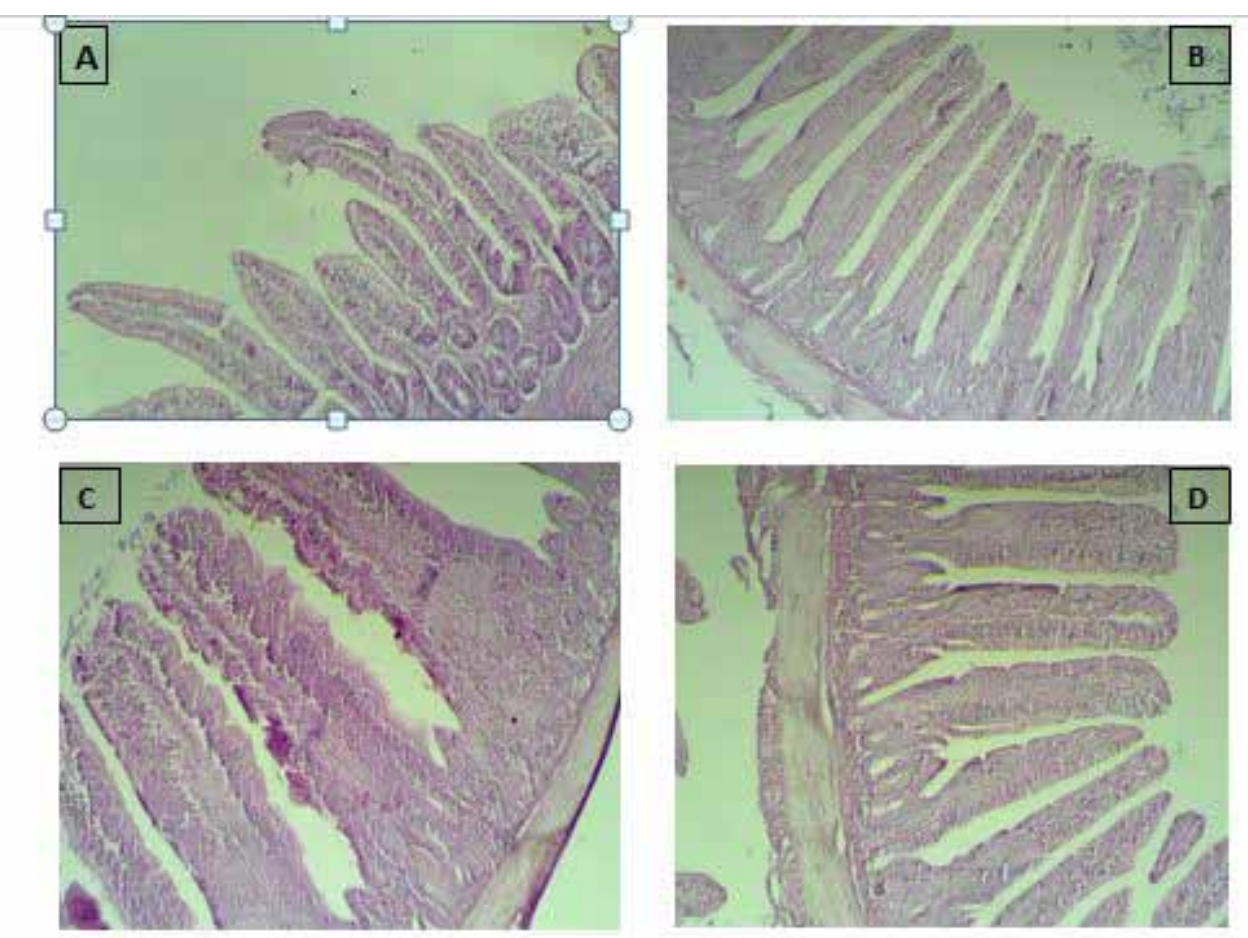

A: The control treatment $T 1$, Irregular length and width of villi are observed in Jejunum

(hematoxylin and eosin tincture) $200 x$

B: treatment T2, regular length and width of villi are observed in Jejunum and the activity of the crypts region (hematoxylin and eosin tincture) $200 x$.

C: treatment $T 3$, and an increase in cellular activity is observed in the crypts region in the Jejunum (hematoxslin and eosin tincture) 200x

D: T4 treatment. It is noted that the length and width of the villi are regular and the cellular activity increases in the crypts region in the ileum (hematoxylin and eosin tincture) 200x

Figure (1) The effect of treatments on some histological traits of Broiler Ross 308 
Table 3: The effect of injecting hatching eggs with nanosilver the length and width of villi and depth of crypts in the Ileum of the broilers.

\begin{tabular}{|l|c|c|c|}
\hline \multirow{2}{*}{ Treatments } & \multicolumn{3}{|c|}{ Average \pm standard error (mm) } \\
\cline { 2 - 4 } & Length of villi & Width of villi & Depth of crypts \\
\hline T1 & $4.90 \pm 0.05 \mathrm{f}$ & $1.13 \pm 0.02 \mathrm{e}$ & $2.47 \pm 0.02 \mathrm{~d}$ \\
\hline T2 & $9.33 \pm 0.03 \mathrm{a}$ & $2.19 \pm 0.01 \mathrm{~b}$ & $2.88 \pm 0.02 \mathrm{~b}$ \\
\hline T3 & $7.86 \pm 0.03 \mathrm{c}$ & $2.20 \pm 0.02 \mathrm{~b}$ & $2.51 \pm 0.06 \mathrm{c}$ \\
\hline T4 & $6.01 \pm 0.08 \mathrm{e}$ & $1.82 \pm 0.02 \mathrm{c}$ & $3.14 \pm 0.01 \mathrm{a}$ \\
\hline T5 & $7.05 \pm 0.10 \mathrm{~d}$ & $1.61 \pm 0.01 \mathrm{~d}$ & $3.12 \pm 0.01 \mathrm{a}$ \\
\hline T6 & $8.51 \pm 0.05 \mathrm{~b}$ & $1.86 \pm 0.03 \mathrm{c}$ & $2.89 \pm 0.04 \mathrm{~b}$ \\
\hline T7 & $8.64 \pm 0.01 \mathrm{~b}$ & $2.46 \pm 0.02 \mathrm{a}$ & $* *$ \\
\hline Level of significance & $* *$ & $* *$ & \\
\hline
\end{tabular}

The averages that have different letters within one column differ significantly among themselves at the level of $*(\mathrm{P}<0.05)$ and $* *(\mathrm{P}<0.01)$. TheT7,T6,T5,T4,T3,T2,T1 coefficients are a control treatment without injection and injection, at concentrations of $14,12,10,8,6,4$ of nanosilver solution, respectively.
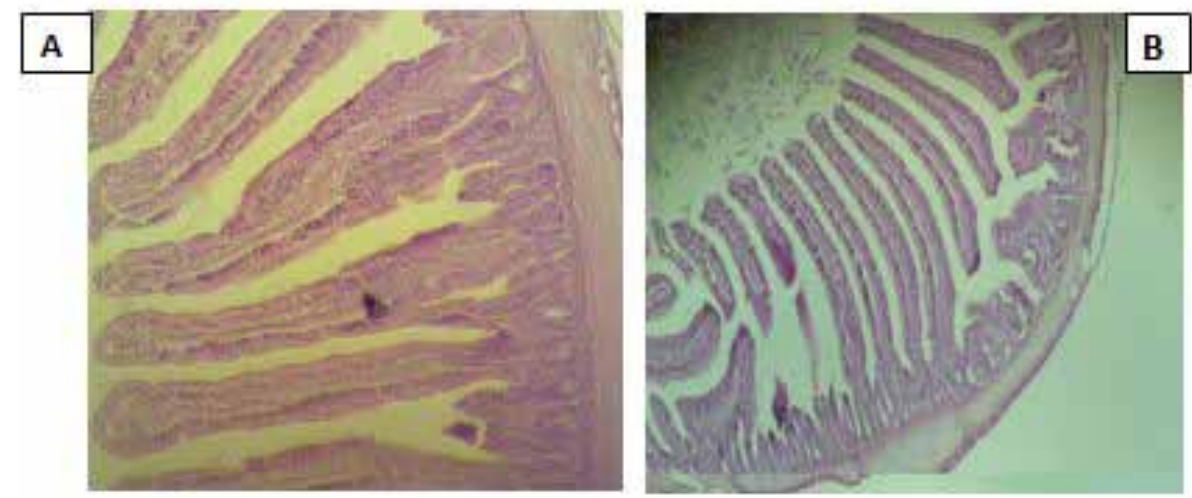

I

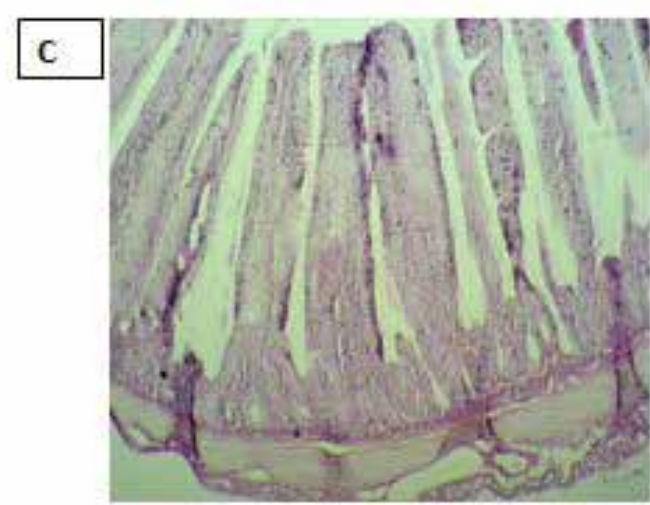

A: T5 treatment. It is noted that the length and width of the villi are regular and the cellular activity increases in the crypts region in the ileum (benatowylin and eosin tincture) $200 x$. B: treatment $T 6$. It is noted that the length and width of the villi are regular and the cellular activity increases in the crypts region in the ileum (hematoxylin and eosin tincture) $200 x$. C: treatment T7. It is noted that the length and width of the villi are regular and the cellular activity increases in the crypts region in the ileum (hematoxylin and eosin tincture) $200 x$.

Figure (2) The effect of treatments on some histological traits of Broiler Ross 308 


\section{Conclusions}

It can be concluded from the experiment to add different concentrations of nano Silver concentrations $(0,4,6,8,10,12,14 \mathrm{ppm})$ at age 17.5 days of embryonic age. A significant effect in improving some histological traits of Broiler Ross 308, We recommend using other nanomaterials and injection them at different ages of the hatching eggs and knowing their effect on some histological traits of Broiler Ross 308.

Conflict of Interest: None

Funding: Self

Ethical Clearance: Not required

\section{References}

1. Fadhel Rasoul Abbas Al-Khafaji, Effect of early feeding by incubation of hatching eggs with ascorbic acid,arginine and maltose sugar in some productive, physiological, microbial and histological traits of broilers. PhD thesis. Faculty of Agriculture - University of Baghdad. 2012.

2. Al-Jubouri Hashem Hadi Dakhil. The effect of injection of hatching eggs with nano silver on hatching, productive, physiological and microbial traits of broilers exposed to heat stress. Master Thesis: Faculty of Agriculture, Al-Qasim AlAkhdar University. 2018.

3. Al-Shukri Aqeel Yousef Abdul Nabi. The effect of adding betaine, vitamin $\mathrm{C}$, and local mixture with drinking water on relieving heat stress in broilers. $\mathrm{PhD}$ thesis, College of Agriculture - University of Baghdad. 2011.

4. Albanese, A, P.S. Tang, W.C.W. Chan. The effect of nanoparticle size, shape, and surface chemistry on biological systems. Annu Rev Biomed Eng.2012;14:1-16.

5. Awad,W.A., J.Bohm, E. Razzazi- Fazeli, K. Ghareeb, and J. Zentek.2006. Effect ofAddition of aprobiotic microorganism to broiler Diets contaminated with deoxy nivalenol on performance. Histological Alterations of intestinal villi of broiler chickens. Poultry science 85: 974-979.

6. Djolai, M., L. Somer, D. Damjanov, L. Hadnadjev, and D. Krojelac. Volume density of intestinal glands in clinical remission of ulcerative colitis. Folia Anatomica. 1998, 26:56-57.

7. Duncan, D.B. 1955. Multiple Rang and Multiple
F-test. Biometrics.11:4-42.

8. Edens, F.W., A.H. Cantor, A.J. Pescatore, and J.L. Pierce. Effect of Dietary selenium on small intestine villus integrity in Reovirus-challenged Broilers. International Journal of Poultry Science 2009. 8(9):829-835.

9. Emily. K. Hill and Li. Julang. Current and future prospects for nanotechnology in animal production. Journal of Animal Science and Biotechnology. 2017, 8:26.

10. Feng, Q.L.; Wu, J.; Chen, G.Q.; Cui, F.Z.; Kim, T.N.; Kim, J.O. Mechanistic study of the antibacterial effect of silver ions on escherichia coli and staphylococcus aureus. J.Biomed. Mater. Res., 2000. 52, 662-668.

11. Jiang, W, Kim BYS, Rutka JT, WCW. Chan. Nanoparticle-mediated cellular response is sizedependent. Nat Nanotechnol. 2008; 3:145-50.

12. Katarzyna Ognik, Iwona Sembratowicz, Ewelina Cholewińska, Łukasz Wlazło, Bożena, Nowakowicz-Dębek, Radosław Szlązak, Krzysztof Tutaj. The effect of chemically-synthesized silver nanoparticles on performance and the histology and microbiological profile of the jejunum in chickens, Ann. Anim. Sci., 2016. Vol.16,No.2 439-450.

13. Lansdown, A.B.G. A review of the use of silver in wound care: Facts and fallacies. Br. J. Nurs., 2004. 13,6-19.

14. Lane Pineda, André Chwalibog, Ewa Sawosz, Anna Hotowy, Jan Elnif, and Filip Sawosz.. Investigating the Effect of In Ovo Injection of Silver Nanoparticles on Fat Uptake and Development in Broiler and Layer; J.Nanotechnol. 2012. 8,02-786.

15. National research council. Nutrient requirement of poultry gthEdn. National Academy press. Washington .D.C.USA. 1994.

16. Richard, H.C., and F.H. Bird., Duodenal villus and epithelial cellular migration in conventional and germ- free chicks Sci., 1973. 52:2276-2280.

17. Saki, A.A and J. Salary. The Impact of in ovo Injection of Silver Nanoparticles, Thyme and Savory Extracts in Broiler Breeder eggs on Growth Performance, Lymphoid-Organ Weights, and Blood and Immune Parameters of Broiler Chicks. Poultry Science Journal, 2015.3 (2): 165-172.

18. SAS, Statistical Analysis System, User's Guide. Statistical. Version $9.1^{\text {th }}$ ed. SAS. Inst. Inc. Cary. N.C. USA. 2012. 